\title{
Análisis de la tabla de MEDIdas de SUSTANCIAS CONTROLADAS Y SUJETAS A FISCALIZACIÓN, VIGENTE EN ECUADOR, EN TORNO A LA CONFIGURACIÓN LEGAL DEL DELITO DE TRÁFICO DE DROGAS ${ }^{1}$
}

\author{
YUDITH LÓPEZ SORIA ${ }^{2}$
}

\section{RESUMEN}

En el Capítulo Tercero sobre los Delitos contra el Buen Vivir del Código Orgánico Integral Penal, Sección Segunda, encontramos regulados los Delitos por la producción o tráfico ilícito de sustancias catalogadas sujetas a fiscalización, y exactamente en el artículo 220, se regula la figura delictiva del Tráfico ilícito de sustancias catalogadas sujetas a fiscalización.

El análisis de este tipo penal nos llevó a concluir que es de configuración legal insuficiente y defectuosa en el COIP, toda vez que la tabla de cantidades de sustancias catalogadas y sujetas a fiscalización, vigente en el Ecuador, para poder calificar la escala o las escalas a las que se comete el delito, no se ajusta al total contenido de la ley, exactamente al último párrafo dentro de este mismo tipo penal, dispone que: "La tenencia o posesión de sustancias estupefacientes o psicotrópicas para uso o consumo personal en las cantidades establecidas por la normativa correspondiente, no será punible".

1 Artículo entregado por la autora el 25 de julio de 2016 y aprobado el 23 de noviembre de 2016.

2 Abogada, Máster en Derecho Penal, Profesora de la Universidad Regional Autónoma de los Andes. 
Vislumbramos además, que al incidir en la configuración legal, incidirá también en su integración y aplicación, y por ende, encontrará pronunciamientos judiciales, que de aplicarse tal y como prevé la ley, encontrarán conflictos importantes entre los principios constitucionales de legalidad (nullum crime, nulla poena sine lege) y ante la duda a favor del reo, (in dubio pro reo). Para demostrarlo iniciaré este análisis.

\section{PALABRAS CLAVE}

Tráfico de drogas, cantidades permitidas, cantidades penalizadas. legalidad y ante la duda, a favor del reo

\section{ABSTRACT}

On Third Chapter entitled Crimes against Good Living of the COIP, on its Second Section, we find regulated the Crimes of Production or Illicit Traffic of Substances Cataloged, and Subject to Inspection, and precisely article 220 regulates the figure of illicit traffic in scheduled substances subject to inspection.

The analysis of this criminal type led us to conclude that there is an inadequate and defective legal configuration in the COIP, because the table of quantities of substances cataloged and subject to control, which exist in Ecuador, in order to qualify the scale or scales this activity is considered a crime, does not conform to the full content of Criminal Law, more exactly the last paragraph within this same article, which states that: "The possession or possession of narcotic or psychotropic substances for personal use or consumption in the amounts established by the corresponding regulations, shall not be punishable." 
We also perceive that by admitting the influence of its legal configuration, it will also affect the integration and application of this criminal type, and therefore, will find judicial pronouncements that, if implemented as provided for by law, will create important conflicts between the constitutional principles of legality, and when in doubt, in favor of the defendant. In order to demonstrate this hypothesis, let us begin the analysis.

\section{KEY WORDS}

Drug traffic, permitted quantities, penalized amounts, legality, and the principle when in doubt, in favour of the defendant

\section{INTRODUCCIÓN}

Es vital lograr una ley penal clara, capaz de aplicarse con seguridad jurídica, en la que vaya implícita toda una serie de garantías y principios de respaldo constitucional e internacional, que reúna las exigencias establecidas tanto doctrinalmente, como en la esfera práctica, sin embargo, realizado un análisis pormenorizado del delito de Tráfico de sustancias catalogadas y sujetas a fiscalización, previsto en el artículo 220 del Código Orgánico Integral Penal, nos percatamos de que esta configuración legal es imprecisa, oscura, contradictoria y, en consecuencia, violatoria de principios constitucionales tan importantes como el de legalidad -nullum crime, nulla poena sine lege- y el de, ante la duda a favor del reo -in dubio pro reo-.

El asunto estriba en que para poder calificar el tipo penal es preciso remitirse a la tabla de sustancias catalogadas y sujetas a 
fiscalización, publicada en el Registro Oficial N. . 288, de 14 de julio de 2014, R.O. 002 CONSEP-CD-2014, la cual establece las cantidades según cada sustancia allí prevista.

Este trabajo persigue entonces como objetivo, demostrar y argumentar estas incongruencias que al ser legales, trascienden a importantes vulneraciones, incluso de principios constitucionales y proponer, además, una solución a dicha problemática legal. Se hizo necesario analizar la droga como sustancia ilícita, el delito de tráfico de drogas, la configuración legal del tipo penal previsto en el art. 220 del COIP, el contenido de la tabla de cantidades de sustancias catalogadas, así como hacer un somero análisis en aras de las restricciones de páginas para un artículo científico, sobre los principios de legalidad y ante la duda a favor del reo, que traemos a colación en nuestro análisis.

\section{Drogas, sustancias estupefacientes, psicotrópicas o catalogadas y sujetas a fiscalización}

El concepto de Droga, según la OMS, Organización Mundial de la Salud, e incluso, desde la óptica farmacológica, resulta aplicable a cualquier sustancia terapéutica o no, que introducida en el organismo humano, a través de cualquier mecanismo, ya sea ingestión, inhalación, administración intramuscular o intravenosa, etc., sea capaz de actuar sobre el sistema nervioso central de la persona que la consume y le provoca un cambio en su comportamiento, cambio que puede manifestarse en una alteración física o intelectual, una experimentación de nuevas sensaciones o una modificación de su estado psíquico; generalmente este cambio de comportamiento se caracteriza por: 
- El deseo abrumador o necesidad de continuar consumiendo esa sustancia, que redunda en lo que conocemos como dependencia psíquica;

- Necesidad de aumentar la dosis para aumentar los mismos efectos, conocido como, tolerancia; y,

- La dependencia física u orgánica de los efectos de la sustancia, que hace verdaderamente necesarios su uso prolongado, para evitar el síndrome de abstinencia.

Según la Convención Única de 1961, enmendada el 8 de agosto de 1975, los estupefacientes son sustancias destinadas a mitigar el dolor, pero que su uso indebido puede dar lugar a una toxicomanía.

En la Convención de las Naciones Unidas contra el Tráfico Ilícito de Estupefacientes y Sustancias Psicotrópicas, BOE, N. ${ }^{\circ}$ 270/1990, de 10 de noviembre de 1990, se hace una remisión a lo regulado en los dos instrumentos anteriormente señalados. Según ésta, por estupefacientes, se entiende cualquiera de las sustancias, naturales o sintéticas, que figuran en la lista I o la lista II de la Convención Única de 1961 sobre Estupefacientes enmendada por el Protocolo de 1972, encontrando que sustancia psicotrópica sería cualquier sustancia, natural o sintética, que figure en las listas I, II, III o IV del Convenio sobre Sustancias psicotrópicas de 1971.

Son tres los grupos principales de las sustancias psicotrópicas, según los efectos generados en el sistema nervioso central:

- Las depresoras;

- Las estimulantes; y,

- Las perturbadoras o alucinógenas. 
Existen en la naturaleza, tantas sustancias naturales que encuadran en este concepto, que nos hace pensar que su uso moderado y terapéutico estaría correcto. Sin embargo, es precisamente su uso desmedido o indebido, el que ha trascendido a la regulación jurídico-penal de su consumo en ocasiones, y el intercambio comercial, en otras, pues en la mayoría de casos, este intercambio se basa en la acción desmedida y ambiciosa, de un grupo importante de seres humanos, que con ánimo de lucro, insisten en distribuir todas estas sustancias en la población mundial a cambio de cuantiosas ganancias monetarias.

Así, todas las naciones han llegado a la necesidad de la regulación jurídica del delito de Tráfico de Drogas.

\section{Tráfico de Drogas}

Para concretar este análisis es preciso dejar definido el término tráfico, que, de acuerdo al Derecho Mercantil, da la idea de comercio, mercantilidad, de habitualidad en la actividad comercial y persecución de lucro, solo que hablando de drogas se convierte en un tráfico, en una comercialización, en una mercantilidad ilícita, una, por el objeto material del delito, en este caso la droga, y sus efectos, en otro sentido, dada la ilicitud por la falta de autorización o licencia para expender, o comercializar la droga en cuestión.

De modo que la difusión indiscriminada y el mal uso de las drogas, generaron la necesidad de intervención jurídica, tanto para su consumo, como para su distribución.

Hace aproximadamente un siglo, surgieron las primeras normas represoras sobre el tema referente a la droga, pues con el 
aumento del consumo y del comercio, las leyes fueron adaptadas e incrementadas, e incluso, arreciadas, con la finalidad de impedir la diseminación de las drogas, sobre todo tratando de neutralizar la distribución que causa efectos tan nocivos, tanto en el ser humano que la consume, como en la familia o parte de la sociedad en la que está incluido él.

Estos delitos relativos a drogas tóxicas son delitos que clasifican por su resultado como delitos de peligro, para muchos teóricos y operadores del Derecho penal son delitos con los que se pretende evitar una futura lesión del bien jurídico protegido, que en este caso es la salud pública, en la mayoría de los ordenamientos jurídico-penales del mundo.

Claro que basta la puesta en peligro de un bien jurídico, para considerarlo, junto con otros elementos, que constituye un delito, pero es obvio que, la mera presencia de una cantidad de droga no puede implicar la existencia de un delito si no se acompaña de un cierto riesgo, riesgo que debe de ser determinado en primer lugar, de manera objetiva, estableciendo unos parámetros y en segundo, personalizándolo según las circunstancias concretas del caso y del autor.

3. El Principio Nullum crime, nulla poena sine lege, (Legalidad) y su vínculo con este tipo penal

Bacigalupo, en este aspecto, en su libro Principios Constitucionales del Derecho Penal, señala que:

Desde 1978 la validez de los textos legales y de las interpretaciones del Código Penal depende, a diferencia de lo que ocurría antes, de su compatibilidad con principios 
superiores. Más aun, la aplicación del derecho penal se debe llevar a cabo, en principio, mediante la técnica de una interpretación "conforme a la Constitución, es decir, que los tribunales ordinarios deben aplicar las normas de tal manera "que una ley de contenido ambiguo o indeterminado se determina por el contenido de la Constitución" y que "no cabe declarar la nulidad de una ley que pueda ser interpretada en consonancia con la Constitución". Asimismo, a los derechos fundamentales se les reconoce un efecto irradiante sobre el derecho ordinario. Está claro que no es posible un análisis de todos y cada uno de los efectos que la Constitución ha tenido sobre el derecho penal material. Por tanto, sólo nos referiremos a un principio básico del derecho penal democrático: el principio de legalidad ${ }^{3}$.

El Nullum crime sine lege scripta, stricta y praevia destaca aspectos esenciales como ley escrita y ley estricta, esto es, rige el principio de certeza y se afirma la legalidad criminal.

El Nulla poena sine lege, de base constitucional también, refuerza el carácter garantista del principio de legalidad, es así, que no pueden imponerse más penas que las establecidas por el legislador previamente, tampoco se pueden sustituir penas y, menos aún, crearlas o inventarlas.

El ordenamiento jurídico penal ecuatoriano reconoce, igualmente, el principio de legalidad, así queda establecido que ningún hecho puede considerarse delito si una ley previamente, no lo ha declarado antes

3 Bacigalupo, E., Principios Constitucionales del Derecho Penal, Buenos Aires: Editorial Hammurabi S.R.L. 1999. 
de su perpetración y tampoco puede imponerse una pena, si no se encuentra descrita en la ley con anterioridad a la comisión del delito.

Esta regla determina que en materia penal rija el principio de reserva de ley. Esta reserva de ley significa que la materia penal debe ser regulada en virtud de disposiciones emanadas de aquel poder estatal que, según las leyes fundamentales, tiene la facultad de legislar. Es decir, son normas establecidas por el Poder Legislativo, lo cual resulta fácil de comprender, es decir, no cualquier persona ni natural, ni jurídica, puede ostentar la facultad de crear leyes.

Es reconocido como principio de legalidad la prevalencia de la ley sobre cualquier actividad o función del poder público. Esto quiere decir que, toda disposición estatal que emane de su poder, debe estar regido por la ley, y nunca por la voluntad de los individuos que conforman al Estado como ente jurídico, así como, que los Tribunales a la hora de decidir un determinado conflicto legal, deben aplicar las fuentes de Derecho reconocidas en su ordenamiento jurídico penal, entre ellas y como primera, la ley.

El principio de legalidad constituye un principio rector y justo dentro del Derecho Penal, cuya función es la de garantizar el respeto de los Derechos del ciudadano, y esa garantía dentro del principio de legalidad se traduce en:

Garantía Criminal: Consiste en que ningún hecho puede ser considerado como delito, sin que una ley anterior lo haya calificado como tal.

Garantía Penal: Esta garantía va encaminada a que no se podrá imponer una pena que no haya sido establecido previamente por la ley. 
Garantía Jurisdiccional: Expone que nadie podrá ser condenado sino en virtud de sentencia firme, pronunciada por un tribunal; es decir, exige que tanto la existencia de un delito, como la imposición de la pena, sean determinadas por una sentencia judicial, estableciéndose, además, al juez de lo penal como único competente para emitir dicha sentencia.

Garantía de Ejecución: Esta garantía expone que no podrá ejecutarse pena alguna en forma distinta de la prescrita por la ley y reglamentos, implica que la pena ejecutada se debe hallar sujeta a una regulación legal.

Así como lleva este principio a garantías, también lleva implícita exigencias o requisitos para atender adecuadamente a las garantías que está obligado a presentar; estas son:

La reserva de ley: Cuando el Estado hace uso del Ius Puniendi o facultad de castigar, no basta que la ley sea quien defina las conductas punibles, ni tampoco bastaría que la ley sea positiva, o sea, escrita, sino que toda ley que esté escrita, deba ser clara y concreta, sin acudir a términos vagos o equívocos que dejen en la indefinición el ámbito de lo punible, es decir, que el legislador debe dejar palpable y definido qué es lo castigado mediante la norma penal.

El principio de taxatividad: Esta exigencia, que se conoce como principio de taxatividad, está vinculada a la seguridad jurídica y a la igualdad en la aplicación de la ley y encierra la obligatoriedad de que la ley penal sea redactada de modo claro, preciso y comprensible.

La prohibición de Retroactividad: La política criminal es la facultad del Estado para criminalizar ciertas conductas que culminan y se materializan, a través de la creación de normas 
jurídicas encaminadas a prevenir y reprimir la criminalidad; si debe de existir una ley que defina las conductas que se consideran punibles, por lógica, esta ley debe de estar vigente al momento en que se cometen los hechos. Por regla, la ley penal es irretroactiva, pero excepcionalmente, y siempre que sea más beneficiosa al encausado, podrá aplicarse a hechos acaecidos con anterioridad a su entrada en vigor (aplicación retroactiva).

La prohibición de analogía: Como ya sabemos, la analogía es la relación de semejanza entre cosas distintas, y según esta definición y adecuándola al Derecho penal, se puede decir que el principio de legalidad impone al juez penal la prohibición de la ampliación de la norma a casos que no están contemplados en la fórmula legal. Siendo así, el juez no podrá salirse de los límites que imponga la ley y aplicarla a supuestos o casos, no previstos en la misma.

\section{Principio in dubio pro reo, (ante la duda a favor del reo) y su contenido}

Existe un consenso extendido entre los juristas más renombrados, pues coinciden en adjudicar el nacimiento del favor rei, al movimiento iluminista, no obstante, este aforismo latino, in dubio pro reo, está históricamente vinculado con la consagración del sistema de libre convicción del juez para apreciar la prueba, teniendo como efecto la supresión de la pena por la simple sospecha conocida antiguamente, como la pena extraordinaria y con la adopción de la máxima ne bis in idem, por la cual "nadie puede ser juzgado dos veces por lo mismo".

MAIER, manifiesta que: 
Aunque se discute sobre el verdadero nacimiento histórico de la máxima, su concepción actual proviene directamente del Iluminismo y del movimiento político que el formó, cristalizado en la presunción de inocencia declamada por el artículo 9 de la Declaración de los Derechos del hombre y el ciudadano. En verdad, la afirmación del aforismo viene históricamente unida a la supresión del sistema de prueba legal y a la imposición de la íntima o libre convicción en la valoración de la prueba; por lo demás, el aforismo solo alcanza su real valor adherido al ne bis in idem, esto es, suprimido cualquier tipo de non linquet $o$ absolutio $a b$ instantia y la pena aminorada contra el sospechoso (poena extraordinaria), pues solo así el mandato de absolver, cuando no se alcanza la certeza sobre el hecho punible imputado, tiene el sentido de una garantía material real. Esto, según creo, demuestra que todo el conjunto de seguridades individuales del Iluminismo conforma el sentido actual del aforismo ${ }^{4}$.

Según GARCíA RADA, "la aplicación del principio in dubio pro reo, en caso de duda o de conflicto en el tiempo, de leyes penales, [implica que] el Juez se inclinará por la norma que sea más favorable al reo"s.

El término in dubio pro reo constituye una expresión latina que generalmente es traducida como: "ante la duda a favor del reo", y usualmente conocida como "la duda favorece al reo". Expresa el principio jurídico de que en caso de duda, por ejemplo, por insuficiencia probatoria, se favorecerá al imputado o acusado, reo. 
Este principio es uno de los pilares del Derecho penal, que va íntimamente ligado al principio de legalidad y, así mismo, al de inocencia.

El principio in dubio pro reo es considerado una regla de garantía constitucional esencial en todo proceso penal, y tiene dos dimensiones que se deberían distinguir: una es la dimensión normativa y otra la dimensión fáctica.

La dimensión fáctica del in dubio pro reo se refiere al estado individual de duda o certeza de los jueces sobre determinado medio probatorio, o sobre el resultado de dicho medio probatorio, lo cual pertenece a la esfera íntima del juez; así cuando éste está realmente convencido respecto del sentido de una prueba que ha percibido directamente, emitirá entonces la correspondiente sentencia condenatoria.

Por el contrario, la dimensión normativa se manifiesta en la existencia de una norma que impone a los jueces la obligación de absolver de culpabilidad, exonerar de responsabilidad penal, liberar de sanción, cuando no se hayan podido convencer de la culpabilidad del acusado o de condenar por la hipótesis más favorable, a éste. Esta norma es vulnerada cuando se condena, sin haber alcanzado tal convicción.

Así, por ejemplo, vulnerará la norma que surge del principio in dubio pro reo un Tribunal que condene únicamente sobre la base de las declaraciones testificales que no expresan sino dudas, o invoque exclusivamente aportes o declaraciones policiales que sugieren sospechas o indicios, no verificados. Es claro que en tales casos, el juez o tribunal no puede fundamentar su certeza en la duda o la mera sospecha de los testigos o de los policías, y si 
en estas condiciones ha condenado, habrá infringido, entonces, el principio in dubio pro reo, en tanto constituye una norma sustantiva, introductoria, una máxima legal, que debe observar todo juzgador, en la aplicación de la ley penal a la hora de juzgar a un ser humano como presunto responsable de determinado hecho delictivo.

Como era de esperarse en un estado democrático de derecho, el ejercicio del poder punitivo está sujeto a una serie de limitaciones conformes con los principios que salvaguardan las garantías en relación a la ciudadanía y en una sociedad garantista, el intervencionismo estatal no puede vulnerar la dignidad y seguridad de sus ciudadanos, pues el poder estatal no es absoluto.

De este modo, una serie de reglas básicas contenidas en la carta de principios, o Constitución de cualquier país, como es el caso también de la República del Ecuador, regulará los límites al ius puniendi que como facultad tiene el Estado, entre esos límites, contamos con el principio In dubio pro reo.

Según MIR PUIG:

Son tres los componentes de las respectivas limitaciones punitivas. El estado de derecho, de donde se origina el principio de legalidad; y estado social, donde se extraen los principios de utilidad de la intervención penal, el principio de subsidiaridad y el carácter fragmentario del derecho penal y el principio de exclusiva protección de bienes jurídicos; y por fin, el estado democrático, que exige la adopción del principio de humanidad de las penas, el principio de 
culpabilidad, el principio de proporcionalidad y el principio de resocialización ${ }^{6}$.

Tratándose de una rama del Derecho de la naturaleza del Derecho penal, donde las consecuencias injustas o ilegales, del proceso resultan de difícil y, a veces, de imposible reparación, es necesario respetar estos principios y resguardarlos con suma cautela, no en balde, es un derecho de mínima intervención o de última ratio.

\section{Análisis crítico del tipo penal de Tráfico de Sustancias catalogadas sujetas a fiscalización, presente en el art. 220 del COIP en una configuración violatoria de los principios legalidad y ante la duda a favor del reo.}

Comencemos esta parte consignando textualmente el art. 220 del COIP, para de este modo, analizar detalladamente su estructura y las peculiaridades del caso que les planteamos.

Artículo 220.- Tráfico ilícito de sustancias catalogadas sujetas a fiscalización.- La persona que directa o indirectamente sin autorización y requisitos previstos en la normativa correspondiente:

1. Oferte, almacene, intermedie, distribuya, compre, venda, envíe, transporte, comercialice, importe, exporte, tenga, posea o en general efectúe tráfico ilícito de sustancias estupefacientes y psicotrópicas o preparados que las contengan, en las cantidades señaladas en las escalas previstas en la normativa correspondiente, será sancionada con pena privativa de libertad de la siguiente manera:

6 MIR PUIG, S. Derecho Penal. Parte General. Barcelona: Tirant lo Blanch, 2004. 
a) Mínima escala de dos a seis meses.

b) Mediana escala de uno a tres años.

c) Alta escala de cinco a siete años.

d) Gran escala de diez a trece años.

2. Oferte, almacene, intermedie, distribuya, compre, venda, envíe, transporte, comercialice, importe, exporte, tenga, posea o en general efectúe tráfico ilícito de precursores químicos o sustancias químicas específicas, destinados para la elaboración ilícita de sustancias estupefacientes y psicotrópicas o preparados que las contengan, será sancionada con pena privativa de libertad de cinco a siete años.

Si las sustancias estupefacientes y psicotrópicas o preparados que las contengan, se oferten, vendan, distribuyan o entreguen a niñas, niños o adolescentes, se impondrá el máximo de la pena aumentada en un tercio. La tenencia o posesión de sustancias estupefacientes o psicotrópicas para uso o consumo personal en las cantidades establecidas por la normativa correspondiente, no será punible?

A decir de ZAFFARONI:

Los delitos de intención el autor tiene en vista un resultado que no necesariamente y a veces nunca- debe alcanzar. En los delitos cortados de resultado el tipo queda consumado con la acción, pero el sujeto tiene en mira un hecho que se debería producir después de ésta y sin su intervención. En los delitos incompletos de dos actos, la conducta típica

7 Código Orgánico Integral Penal de Ecuador, Diario Oficial de la República del Ecuador, Quito, 10 de febrero de 2014. 
es el medio para la realización de una segunda acción del autor. El grupo de los delitos de tendencia se caracteriza porque la voluntad de la acción asume una modalidad particular, que no se exterioriza en forma completa. Con la pura exteriorización de la voluntad no puede saberse si asume o no esa modalidad, sino que únicamente en algunos casos puede descartarse ésta ${ }^{8}$.

Cuestión similar ocurre con el delito de tráfico de drogas previsto en el art. 220 del COIP, que analizaremos. Con independencia a la voluntad del autor, en definitiva, la calificación o tipificación legal que hagamos depende de los hechos encuadrados una vez más en la norma, el autor no ha tenido en cuenta este particular, dentro de su intención; los límites para la calificación del ilícito vienen impuestos por la ley.

El Tráfico de Droga, previsto en el art. 220 del COIP, tiene como figura delictiva, la peculiaridad de tratarse por una serie amplia de verbos rectores o nucleares, que amplían considerablemente las posibilidades de incurrir en este ilícito penal, lo que se conoce en la doctrina como una cascada de verbos rectores, pues así encontramos que se incurre en este delito si se oferta, almacena, intermedia, distribuya, compra, venda, envía, transporta, comercializa, importe, exporte, tenga o posea o en general efectúe el tráfico ilícito de sustancias estupefacientes y psicotrópicas o preparados que las contengan.

Véase que cualquiera de estos verbos refleja acciones delictivas, lo que reafirma que la modalidad de comisión de este delito es la acción, el acto, el efectuar, el realizar algo. 
Pero discurre entre tantos verbos que deja claro que no basta con que usted difunda la droga en cuestión, onerosamente, (comprar o vender), o sea, a cambio de dinero, puede hacerlo también gratuitamente, con el ánimo de compartir, e igualmente, incurriría en este tipo penal, siempre que no tenga ni autorización legal, ni licencia para hacerlo, o puede simplemente transportarla, almacenarla, ofrecerla u ofertarla, distribuirla, mediar para su distribución, importarla al país, exportarla a otro país, enviarla a algún lugar, o sencillamente poseerla o tenerla en su poder, cualquiera de estas acciones implicaría la tipicidad de este delito de tráfico de drogas, siempre que se adhiera el otro elemento que exige el tipo penal concreto, que es, que haga cualquiera de estas acciones en las cantidades reguladas en la normativa correspondiente, a través de las cuales esas cantidades unidas a la naturaleza y características de estas drogas, se convierten en peligrosas para la salud, que a fin de cuentas, es el bien jurídico protegido al tipificarse este delito.

Observemos que en la configuración legal de este tipo penal un verbo lleva al otro, o al final, se necesitan incluso varios verbos que denotarán varias acciones delictivas, que conforman el mismo delito de Tráfico, para completar el círculo de participación necesario para su integración, sobre todo si alcanzare este hecho, en algún momento, la dimensión de crimen organizado.

Por último, el legislador ecuatoriano emplea lo que conocemos como un tipo de bolso legal, previendo que si se quedara por mencionar taxativamente alguna acción, o el futuro deparara una nueva forma de actuar o ejecutar este ilícito penal, en aras de lograr la plenitud en el ordenamiento jurídico penal vigente, entrarían esas acciones a configurar otra forma de integración de este ilícito penal en concreto, pues cabrían en esta frase empleada 
en el art. 220 del COIP: [...] "o en general efectúe tráfico ilícito de sustancias estupefacientes y psicotrópicas o preparados que las contengan". 9

Otro aspecto legal a tener en cuenta para la comprensión íntegra de este injusto penal, es decir, de su configuración legal es evaluar el principio de insignificancia de la conducta vinculada a la droga, cualquiera que esta sea, siempre que esté regulada como tal por las convenciones y listas establecidas al respecto, sería una acción atípica, cuando la cantidad de droga es tan insignificante que resulta incapaz de producir efecto nocivo alguno a la salud, aparejado, obviamente, también a la naturaleza y características de la droga misma.

Este principio, solo se aplica de manera excepcional y restrictiva, cuando la absoluta nimiedad de la sustancia, ya no constituya una droga tóxica o estupefaciente, sino un producto inocuo.

Lo siguiente que debemos observar es que éste es un delito, que tiene la peculiaridad de no poseer un marco penal legal exclusivo, sino, que tiene tantos marcos penales sancionadores, como escalas se han concebido para el tráfico de drogas; por lo que tal y como está previsto, no es posible calificar el delito de tráfico de drogas sin recurrir a la normativa establecida independientemente para determinar la cantidad de droga traficada, a qué sustancia corresponde y de qué cantidad se estaría hablando en cada caso; de ahí que parte de la configuración legal constituya la tabla de sustancias, citada reiteradamente en este material.

9 Código Orgánico Integral Penal de Ecuador, Diario Oficial de la República de Ecuador, Quito, 10 de febrero de 2014. 
Estas cantidades son simples referencias, susceptibles de matizaciones en cada caso concreto, teniendo que valorarse, además, como arriba ya mencionamos, el porcentaje de riqueza de la sustancia, pues éste resulta importante para determinar si existe o no delito. Se utiliza para saber si es capaz de causar riesgos para la salud y supone la proporción del principio activo contenido en ella, aunque solo es relevante en aquellos supuestos en que las cantidades son escasas; obviamente, en este caso debemos valorar lo que se conoce como dureza de la droga en cuestión, y su composición natural o química.

Observamos un Código Orgánico Integral Penal, que persigue, como uno de sus mayores logros, compilar toda la legislación penal vigente en el ordenamiento jurídico penal ecuatoriano; tenemos que salirnos de él y buscar una normativa aún dispersa, es decir, debemos localizar el Registro Oficial N. ${ }^{\circ} 288$, de 14 de julio de 2014, R.O. 002 CONSEP-CD-2014, que contiene las tablas de cantidades de sustancias estupefacientes y psicotrópicas para sancionar el delito de tráfico de drogas de mínima, mediana, alta y gran escala.

Este delito consta de cuatro escalas para su calificación, ya enunciadas en el párrafo anterior, y que, a continuación, plasmamos en este texto dicha tabla, para que analicemos conjuntamente nuestra preocupación legal. 
TABLA N. ${ }^{\circ} 1$

\begin{tabular}{|c|c|r|c|c|c|c|c|c|}
\hline \multicolumn{7}{|c|}{ SUSTANCIAS ESTUPEFACIENTES } \\
\hline $\begin{array}{c}\text { Escala } \\
\text { gramos }) \\
\text { Peso neto }\end{array}$ & \multicolumn{2}{|c|}{ Heroína } & \multicolumn{2}{c|}{$\begin{array}{c}\text { Pasta base } \\
\text { de cocaína }\end{array}$} & \multicolumn{2}{c|}{$\begin{array}{c}\text { Clorhidrato } \\
\text { de cocaína }\end{array}$} & \multicolumn{2}{c|}{ Marihuana } \\
\cline { 2 - 10 } & Mín. & Máx. & Mín. & Máx. & Mín. & Máx. & Mín. & Máx. \\
\hline $\begin{array}{c}\text { Mínima } \\
\text { escala }\end{array}$ & $>0$ & 1 & $>0$ & 50 & $=0$ & 50 & $>0$ & 300 \\
\hline $\begin{array}{c}\text { Mediana } \\
\text { escala }\end{array}$ & $>1$ & 5 & $>50$ & 500 & $=50$ & 2.000 & $>300$ & 2.000 \\
\hline $\begin{array}{c}\text { Alta } \\
\text { escala }\end{array}$ & $>5$ & 20 & $>500$ & 2.000 & 12.000 & 5.000 & $=2.000$ & 10.000 \\
\hline $\begin{array}{c}\text { Gran } \\
\text { escala }\end{array}$ & $>20$ & & $>2.000$ & & $=5.000$ & & $=40,000$ & \\
\hline
\end{tabular}

\begin{tabular}{|c|c|c|c|c|c|c|}
\hline \multicolumn{7}{|c|}{ SUSTANCIAS PSICOTRÓPICAS } \\
\hline $\begin{array}{c}\text { Escala } \\
\text { (gramos) } \\
\text { Peso neto }\end{array}$ & \multicolumn{2}{|c|}{ Anfetaminas } & \multicolumn{2}{|c|}{$\begin{array}{c}\text { Metilendioxifenetilamína } \\
\text { (MDAT) }\end{array}$} & \multicolumn{2}{|c|}{$\begin{array}{c}\text { Éxtasis } \\
\text { (MDMA) }\end{array}$} \\
\hline & Mín. & Máx. & Mín. & Máx. & Mín. & Máx. \\
\hline $\begin{array}{c}\text { Mínima } \\
\text { escala }\end{array}$ & $>0$ & 2,5 & $>0$ & 2,5 & $>0$ & 2,5 \\
\hline $\begin{array}{c}\text { Mediana } \\
\text { escala }\end{array}$ & $>2,5$ & 5,0 & $>2,5$ & 5,0 & $>2,5$ & 5,0 \\
\hline $\begin{array}{c}\text { Alta } \\
\text { escala }\end{array}$ & $>5,0$ & 12,5 & $>5, \mathrm{D}$ & 12,5 & $>5, \mathrm{D}$ & 12,5 \\
\hline $\begin{array}{c}\text { Gran } \\
\text { escala }\end{array}$ & $>12, \mathrm{~S}$ & & $>12, \mathrm{~S}$ & & $>12, \mathrm{~S}$ & \\
\hline
\end{tabular}

Fuente: Tabla del art. 1 Resolución 002 CONSEP-CD-2014 de 9 de julio de 2014, publicado en el 2. ${ }^{\circ}$ Suplemento de Registro Oficial N. ${ }^{\circ} 288$, de 14 de julio de 2014. 
Apreciemos, en primer lugar, que la mínima escala es sancionable, según plantea el inciso a) del artículo 220, cuyo texto íntegro le hemos consignado ut supra.

En este caso, cualquiera que sea el tipo de droga, sería sancionable de dos a seis meses de privación de libertad, pero valoremos que tanto para el caso de las sustancias estupefacientes, como psicotrópicas, las mínimas escalas comienzan según esta tabla en cero gramos $(0 \mathrm{~g})$, pues la unidad de medida para el peso establecida es el gramo, y aquí precisamente radica el problema legal que vislumbramos, no en la unidad de medida, sino, en que comienza a valorarse a partir de 0 gramos.

El inconveniente radica en que si el artículo 220 del COIP establece en su último párrafo que: "La tenencia o posesión de sustancias estupefacientes o psicotrópicas para uso o consumo personal en las cantidades establecidas por la normativa correspondiente, no será punible" $"$.

Evidentemente contradictorio resulta esto, pues si la tabla de gramaje de sustancias comienza por cero gramos, en el caso de todas las sustancias, o sea, heroína, pasta de cocaína, clorhidrato de cocaína, marihuana, anfetaminas, Metilendioxifenetilamína (MDAT) y éxtasis (MDMA) estamos, entonces, ante una encrucijada legal; primero, preguntémonos por qué la tabla no establece de modo taxativo, toda vez que tiene fuerza de ley, cuál es la cantidad permitida para el consumo, no considerada para ser punible en el caso de cada una de estas sustancias; segundo,

10 Código Orgánico Integral Penal de Ecuador, Diario Oficial de la República de Ecuador, Quito, Ecuador, 10 de febrero de 2014. 
si no lo establece la tabla, debió entonces ser elaborada de modo que consigne el comienzo de la mínima escala punible a partir de la cantidad no punible, establecida para tenencia, portación y consumo permitido.

Esta configuración legal enfrenta o pone en confrontación los principios penales otrora enunciados y explicados; primero, el de legalidad, porque si la ley expresamente refiere que de 0 a 300 gramos de marihuana, por poner un ejemplo, estaríamos ante un tráfico de drogas a mínima escala, el juez, en observancia a este principio y en franca obediencia a la ley, debe sancionar a la persona que posea 0,5 gramos de marihuana, llevándolo consigo en su cuerpo, cartera o vestuario, como responsable de un delito de tráfico de droga en mínima escala, obviando entonces lo consignado en el último párrafo del artículo 220 del COIP, que refiere que no será punible la tenencia o posesión de sustancias estupefacientes o psicotrópicas para uso o consumo personal en las cantidades establecidas en la normativa correspondiente, pero resulta que las cantidades establecidas en la normativa correspondiente; comienzan desde cero en cada una de las sustancias catalogadas y sujetas a fiscalización para el Ecuador. Evidentemente, esa cantidad permitida y aludida aquí, por el legislador debe estar implícita en esta tabla, sobre todo por la claridad que amerita la ley penal y la configuración de los delitos, por las consecuencias que arrostran.

Obedeciendo al principio de legalidad, tal y como establece el COIP, el juez actuante debiera sancionar a una persona que porte la cantidad de droga permitida para el consumo humano, por un delito de tráfico de droga, en mínima escala, previsto en el art. 220. a). Pues, analizando cada uno de los verbos rectores consignados en este ilícito penal por el legislador ecuatoriano, 
cabe perfectamente el delito cometido por acción por el hecho de tener o poseer sustancias estupefacientes y psicotrópicas o preparados que las contengan, en las cantidades señaladas en las escalas previstas en la normativa correspondiente, resultando, por ende, sancionada con pena privativa de libertad de dos a seis meses, por encuadrar perfectamente en la mínima escala, si trae consigo, posee, o tiene en su poder, de 0 a 1 gramo de heroína, de 0 a 50 gramos de pasta base de cocaína, de 0 a 50 g de clorhidrato de cocaína, de 0 a 300 gramos de marihuana, de 0 a 2,5 g de anfetaminas, de Metilendioxifenetilamina (MDAT), o Éxtasis (MDMA), cualquiera que sea la sustancia de éstas reguladas como catalogadas y sujetas a fiscalización en el Ecuador.

Por otra parte, es preciso que evaluemos el concepto de posesión. Cuando se refiere a la droga, se piensa que esta posesión va dirigida a traficar, o sea, para poder traficar en cualquiera de sus modalidades, es preciso entonces, primero, tener o poseer, identificado con la disponibilidad de la droga misma, pues ya explicamos el por qué es clasificado como un delito de peligro e incluso, de peligro abstracto.

Este análisis conlleva a que se haga difícil poder identificar $a$ priori, entre un consumidor y un traficante, cuando la posesión de drogas es en cuantías mínimas, aunque no deja de ser un elemento central del delito en cuestión.

Nuestro análisis estriba en que, siguiendo la letra del artículo 220.a), en concordancia con la Tabla de gramaje de sustancias catalogadas, aprobada por el CONSEP y vigente en Ecuador, el juez está obligado a calificar y sancionar la tenencia y portación de inocuas cantidades de droga, tal y como hemos explicado, respetando el principio de legalidad, pero, por otra parte, nos 
encontramos en el dilema que se presenta con la aplicación del principio in dubio pro reo, que ya hemos dejado claro, radica en vertientes como: ante la insuficiencia probatoria, debe proceder el juez dictando un fallo absolutorio a favor del reo, o en segundo término, ante el conflicto de leyes penales de contenido diferente en cuanto a sanciones a imponer, debe acogerse la norma más favorable al reo, o acusado, (art. 5.2 del COIP, principio de favorabilidad), que está inmerso en la doctrina ante el propio principio in dubio pro reo.

Frente a este contenido, el juez debería absolver al acusado, en virtud de que el último párrafo del art. 220 prevé que como causa que excluye la punibilidad como elemento del delito, el legislador ecuatoriano entendió que la tenencia o posesión para uso y consumo personal en las cantidades establecidas en la normativa correspondiente no será punible y bien, pero nos preguntamos: ¿Cuál es la normativa correspondiente? y ¿cuál es la cantidad, si es que la normativa vigente que establece la tabla de gramaje comienza a contar a partir de cero gramos para calificar en mínima escala este delito? Pero en ese caso, estaría el juez, actuando de espaldas al principio de legalidad, y si, a contrario sensu, haciendo aplicación del principio de legalidad de modo íntegro, decide sancionar, según lo que establece la norma de modo expreso y taxativo, entonces quebrantaría el principio in dubio pro reo, y de favorabilidad, ya que pudiendo acoger una norma penal más favorable al reo, decide sancionarle basado en que el precepto legal que dice que, a partir de 0 gramos $(0 \mathrm{~g})$ de cualquiera de las sustancias catalogadas estaríamos ante un delito de tráfico de drogas a mínima escala.

Entendemos entonces que con esta reflexión dejo vislumbrado el enfrentamiento o contraposición que denuncio con este material, 
entre estos dos principios de rango constitucional, el de legalidad y el in dubio pro reo, encontrado al aplicar el precepto legal del art. 220 del COIP, en los términos legales que está regulado actualmente en el Ecuador.

Una tabla correcta y respetuosa de los principios ahora confrontados quedaría así, en cuanto a cantidades, y es nuestra propuesta:

TABLA N. ${ }^{\circ} 2$

\begin{tabular}{|c|r|r|r|r|r|r|r|r|}
\hline \multicolumn{7}{|c|}{ SUSTANCIAS ESTUPEFACIENTES } \\
\hline $\begin{array}{c}\text { Escala } \\
\text { (gramos ) } \\
\text { Peso neto }\end{array}$ & Meroína & $\begin{array}{c}\text { Pasta base de } \\
\text { cocaína }\end{array}$ & \multicolumn{2}{|c|}{$\begin{array}{c}\text { Clorhidrato } \\
\text { de cocaína }\end{array}$} & \multicolumn{2}{|c|}{ Marihuana } \\
\cline { 2 - 9 } & Máx. & Mín. & Máx. & Mín. & Máx. & Mín. & Máx. \\
\hline $\begin{array}{c}\text { Mínima } \\
\text { escala }\end{array}$ & $>0.1$ & 1 & $>2$ & 50 & $>1$ & 50 & $>10$ & 300 \\
\hline $\begin{array}{c}\text { Mediana } \\
\text { escala }\end{array}$ & $>1$ & 5 & $>50$ & 500 & $=50$ & 2.000 & $>300$ & 2.000 \\
\hline $\begin{array}{c}\text { Alta } \\
\text { escala }\end{array}$ & $>5$ & 20 & $>500$ & 2.000 & 12.000 & 5.000 & $=2.000$ & 10.000 \\
\hline $\begin{array}{c}\text { Gran } \\
\text { escala }\end{array}$ & $>20$ & & $>2.000$ & & $=5.000$ & & $=40,000$ & \\
\hline
\end{tabular}




\begin{tabular}{|c|c|c|c|c|c|c|}
\hline \multicolumn{7}{|c|}{ SUSTANCIAS PSICOTRÓPICAS } \\
\hline \multirow{2}{*}{$\begin{array}{c}\text { Escala } \\
\text { (gramos) } \\
\text { Peso neto }\end{array}$} & \multicolumn{2}{|c|}{ Anfetaminas } & \multicolumn{2}{|c|}{$\begin{array}{c}\text { Metilendioxifenetilamína } \\
\text { (MDAT) }\end{array}$} & \multicolumn{2}{c|}{$\begin{array}{c}\text { Éxtasis } \\
\text { (MDMA) }\end{array}$} \\
\cline { 2 - 7 } & Mín. & Máx. & Mín. & Máx. & Mín. & Máx. \\
\hline $\begin{array}{c}\text { Mínima } \\
\text { escala }\end{array}$ & $>0.040$ & 2,5 & $>0.015$ & 2,5 & $>0.015$ & 2,5 \\
\hline $\begin{array}{c}\text { Mediana } \\
\text { escala }\end{array}$ & $>2,5$ & 5,0 & $>2,5$ & 5,0 & $>2,5$ & 5,0 \\
\hline $\begin{array}{c}\text { Alta } \\
\text { escala }\end{array}$ & $>5,0$ & 12,5 & $>5, \mathrm{D}$ & 12,5 & $>5, \mathrm{D}$ & 12,5 \\
\hline $\begin{array}{c}\text { Gran } \\
\text { escala }\end{array}$ & $>12, \mathrm{~S}$ & & $>12, \mathrm{~S}$ & & $>12, \mathrm{~S}$ & \\
\hline
\end{tabular}

\section{Necesidad de claridad de la ley penal}

Como cualquier ley, una característica propia es la claridad y posible comprensión de su contenido, pero en el caso de la Ley penal, que es norma en un derecho reconocido en la actualidad, como de última ratio o mínima intervención, por las implicaciones tan severas que representa, no debe existir norma penal en blanco, ni lagunas legales.

La interpretación de la ley penal se puede definir como fijar el sentido y alcance del espíritu de la ley, es decir, que lainterpretación de la ley penal se debe entender como una operación completa, que exige establecer el significado abstracto de la regla legal, es decir, la intelección de la ley y su significado concreto frente al caso a resolver o aplicación de la ley. 
La historia y evolución del Derecho penal, nos remonta a conocer que en un principio existió un precepto prohibitivo de interpretar las leyes penales, VON BAR fue el primero en establecer estas prohibiciones, posteriormente a este, vinieron otros autores como CARRARA, BECCARIA, por mencionar algunos, pero la historia fue avanzando, se dividieron los poderes del Estado, rompiéndose con ellos las normas que establecían que el soberano o el juez eran los que creaban, aplicaban, ejercían y hasta dictaban sentencia, así que ya en un Estado de Derecho y debido a las necesidades o exigencias imperantes, la ley comenzó a ser interpretada.

Volvemos entonces a invocar el principio de legalidad y con ello a demostrar por qué está siendo vulnerado por la configuración legal aludida en este trabajo, el delito de Tráfico de Drogas, el cual para tipificarse requiere tener en cuenta la tabla en cuestión como parte de la configuración legal del propio tipo penal.

Ya tenemos claramente establecido que este principio es reconocido universalmente, pues se traduce esencialmente en la observancia de todas las normas, es decir, que se manifiesta en todos los ordenamientos en los cuales se tenga que sujetar el poder público a determinadas normas de observancia de modo obligatorio. En materia penal, el principio de legalidad garantiza que el Estado determinará de forma clara en la ley penal, qué infracciones constituyen delito y cuáles constituyen falta; y a la vez, está obligado a señalar las sanciones y las medidas de seguridad que se aplicarán en cada caso de violación a la norma, es decir, en caso de comisión de delito o infracción penal alguna.

Dada la argumentación anterior, podemos observar que la norma establecida en el art. 220 del COIP no es clara, ni precisa, por 
tanto, no cumple con las exigencias reclamadas para la ley penal $\mathrm{y}$, por ende, se vuelve incapaz de asegurar el cumplimiento de las garantías que debiera ceder a favor del acusado en cuestión.

\section{CONCLUSIONES}

Primera: Los tipos penales deben tener una configuración legal capaz de ajustarse a los principios que informan al propio Derecho penal $\mathrm{y}$, en particular, deben ajustarse a los requerimientos legalmente establecidos para la tipicidad, partiendo de la tipicidad como principio mismo.

Segunda: Es difícil que un juez pueda emitir fallos judiciales sancionatorios o absolutorios, correctos e íntegros, en torno a tipos penales que están configurados de modo erróneo o desacertado, acorde a los principios que instruyen al Derecho penal.

Tercera: Se hace necesario reformular la configuración legal del delito de tráfico de sustancias catalogadas y sujetas a fiscalización, (drogas), previsto en el art. 220 del Código Orgánico Integral Penal del Ecuador, específicamente con respecto a la tabla de sustancias vigente, que incide de modo negativo en el tipo penal, pues dicho tipo depende de esta tabla para poder calificarlo con exactitud, lo cual urge, debido a que su formulación actual contrapone y, por ende, vulnera los principios de legalidad y ante la duda a favor del reo, ambos de rango constitucional . 


\section{BIBLIOGRAFÍA}

BaCIGAlupo, Enrique. Principios Constitucionales del Derecho Penal. Buenos Aires: Editorial Hammurabi S.R.L, 1999.

BANDIERI, Luis María. "Control de constitucionalidad y control de convencionalidad: rápido repaso de límites y problemas" [en línea]. Presentado en Novenas Jornadas Internacionales de Derecho Natural: Derecho natural, hermenéutica jurídica y el papel del juez, Universidad Católica Argentina, Facultad de Derecho, Buenos Aires, Argentina. Disponible en: http://bibliotecadigital.uca. edu.ar/repositorio/ponencias/control-constitucionalidadconvencionalidad.pdf, 2013.

BeCCARIA, Cesare. De los Delitos y Las Penas. Buenos Aires: Editorial Orbis, 1984.

BUSTOS, Juan y HORMAZÁBAL, Hernán. Lecciones de Derecho Penal, Tomo I. Madrid: Editorial Trotta, 1997.

CARbonell, Juan Carlos. Derecho Penal: Conceptos y Principios Constitucionales. Valencia: Tirant lo Blanch, 1996.

Cerezo MIR, José. Curso de Derecho Penal Español. Tomo I. Madrid: Editorial Tecnos, 1996.

ClÉRICO, Juan Manuel. “Conciencia e imputación penal. Una aproximación a la luz del principio de finalidad", en 
Revista Prudentia Iuris, N. ${ }^{\circ}$ 74. Disponible en:http:// bibliotecadigital.uca.edu.ar/repositorio/revistas/ conciencia-imputacionpenal-principio-finalidad.pdf, 2012

HASSEMER, Winfried. Persona, mundo y responsabilidad. Bases para una teoría de la imputación en Derecho Penal. Santa Fe de Bogotá: Editorial Nomos, 1999.

FLORES, Pedro. Diccionario de Términos Jurídicos. Lima: Editorial Científica, 1984.

GARCÍA RADA, Domingo. Manual de Derecho Procesal Penal, Lima: Editorial Eddili, 1978.

GÜNTHER, Jakobs. Derecho penal. Parte general. Fundamentos y teorías de la imputación. Madrid: Marcial Pons, Ediciones Jurídicas S.A., 1995.

MAIER, Julio. Derecho procesal penal. Buenos Aires: Editores del Puerto, 1997.

MAIER, Julio y BINDER, Alberto. El Derecho Penal de Hoy, s/d, 1995.

MIR PUIG, Santiago. Derecho Penal. Parte General. Barcelona: Tirant lo Blanch, 2004.

MuÑOZ CONDE, Francisco, y GARCÍA, Mercedes. Derecho Penal. Valencia: Tirant lo Blanch, 1996.

RoXIN, Claus. Derecho Penal. Parte General, Tomo I. Madrid: Editorial Civitas, 1997. 
RUSCONI, Maximiliano. Principio de inocencia e in dubio pro reo. Buenos Aires: Editorial Ad-Hoc, 1997.

URQuiZO, José. Derecho en General. Primera Parte. Perú, 2007.

ZAFFARONI, Eugenio. Derecho penal. Parte General. Buenos Aires: Ediar S.A. Editora, 2002.

\section{LEYES}

- Constitución de la República del Ecuador 2008. Registro Oficial N. ${ }^{\circ} 449$, de 20 de octubre de 2008. Última modificación: 13 de julio de 2011.

- Código Orgánico Integral Penal de Ecuador, Diario Oficial de la República de Ecuador, Quito, 10 de febrero de 2014.

- Resolución 002 CONSEP-CD-2014, de 9 de julio de 2014, publicado en el 2. ${ }^{\circ}$ Suplemento del Registro Oficial N. ${ }^{\circ} 288$, de 14 de julio de 2014. 